\title{
In-vitro and in-vivo evaluation of the antibacterial potential of Typha elephantina
}

\author{
Ahmad, B. ${ }^{1 *}$, Yousafzai, A.M. ${ }^{1}$, Zeb, $A .^{2}$, Khan, A.A. ${ }^{2}$, Attaullah, M. ${ }^{3}$, Ahmad,.$^{3}$ \\ ${ }^{1}$ Department of Zoology, Islamia College, Peshawar, Khyber Pakhtunkhwa, Pakistan \\ ${ }^{2}$ Department of Biotechnology, University of Malakand, Chakdara, Khyber Pakhtunkhwa, Pakistan \\ ${ }^{3}$ Department of Zoology, University of Malakand, Chakdara, Khyber Pakhtunkhwa, Pakistan \\ *Corresponding author: basheer.icup@gmail.com
}

\section{ARTICLE HISTORY}

Received: 18 September 2019

Revised: 16 November 2020

Accepted: 19 November 2020

Published: 25 March 2021

\begin{abstract}
The present study was aimed to evaluate the in-vitro and in-vivo antibacterial effects of the Typha elephantina aqueous extract (TE.AQ), ethanolic extract (TE.ET) and T. elephantina methanolic extract (TE.ME) against eight selected clinical pathogens. The test samples were tested for in-vitro analysis (by disc diffusion method) at different concentrations of 5, 15, 25, 50 and 100 $\mathrm{mg} / \mathrm{dL}$ against both gram positive and gram-negative strains. The highest potential was observed in TE.ME at a concentration of $100 \mathrm{mg} / \mathrm{dL}$ against Pseudomonas aeruginosa exhibiting $19.67 \pm 0.577 \mathrm{~mm}$ zone of inhibition (ZOI). The same fraction also showed good activity against Staphylococus aureus with ZOI of $17.50 \pm 0.70 \mathrm{~mm}$. The TE.ET was found most active against $P$. aeruginosa and Streptococcus pyogenes having ZOI of $18.53 \pm 0.503$ and $16.2 \pm 1.55 \mathrm{~mm}$ respectively at a concentration of $100 \mathrm{mg} / \mathrm{dL}$. The most sensitive bacteria $P$. aeruginosa was selected for in-vivo study (using poultry chicks) for induction of infection in chicks. The effects of TE.AQ, TE.ET and TE.ME were determined at concentrations of $300 \mathrm{mg} / \mathrm{kg}$ body weight based on hematological parameters, liver enzymes and gross pathological findings of lungs and livers. The findings of the in-vivo study in chick's model showed that treatment of experimental animals with TE.ME significantly restored the hematological parameters, liver enzymes and architecture of lungs and livers. Based on scientific evidence, the current study suggests that TE.ME may serve as a best and new natural antibacterial agent and can be used against infections caused by $P$. aeruginosa.
\end{abstract}

Keywords: Typha elephantina, in-vitro and in-vivo, zone of inhibition, Pseudomonas aeruginosa, chicks, aqueous, ethanolic and methanolic.

\section{INTRODUCTION}

Infectious diseases have been the most serious health issue in the world today. Some of the pathogenic bacterial species include Staphylococcus aureus, Bacillus subtilis, Bacillus licheniformis, Escherichia coli, Pseudomonas aeruginosa, Salmonella enterica and Salmonella typhimurium caused various infections in animals and human (Emiru et al., 2019). The consistent use of synthetic antibiotics lead to microbial resistance. Besides these, the antibiotics may also cause adverse effects in the host like hypersensitivity, immune suppression, and other allergic reactions (Ahameethunisa \& Hopper, 2010).

Microbial resistance depends upon their genetic ability to transmit and become resistant to various treatments, which are used as therapeutic agents (Singh, 2015). The increase of bacterial resistance to existing antibiotics has requisite the search for new antibacterial agents and thus has forced the researcher to search new antimicrobial agent from medicinal plants (Lewis, 2013). Medicinal plants have been explored for various pharmacological activities such as antimicrobial, anthelmintic, analgesic, antipyretic and insecticidal activities (Saleem et al., 2020). Plant constituents can be used directly as healing agent as well as act as preliminary materials for the synthesis of drugs or as models of biologically active compounds (Al-Salt, 2012). Plant base antimicrobial agents have least side effects and have higher medicinal effect to heal various diseases (Inglin et al., 2015). Certain bioactive compounds of plants origin like alkaloids, tannin, flavonoid and phenolic, are very important due to its physiological effect on the human body, especially antioxidant activity (Zeb, 2020). So, the analysis of such medicinal herbs are very essential to isolate and employ their active ingredients in medicines for the development of new drugs against the drug-resistant microorganisms (Fankam et al., 2014).

Typha elephantina Roxb is a member of family Typhaceae, locally known as (Barr" in Pakistan). The family Typhaceae consists of one genus (Typha) and several important medicinal plants species (Typha, angustifolia, Typha angustifolia, 
Typha xglauca, Typha latfolia) (Shukla \& Mishra, 2015; Ha et al., 2019). Hence, the aim of the current study was to evaluate invitro and in-vivo antibacterial potential of TE.AQ, TE.ET and TE.ME extract of Typha elephantina leaves against different pathogenic bacterial strains.

\section{MATERIALS AND METHODS}

\section{Plant materials and extraction}

Typha .elephantina (T. elepentenia) was collected from different regions of District Swat and was identified and authenticated by Dr. Muhammad Nisar Ahmad (Professor, Department of Botany, University of Malakand, Khyber Pakhtunkhwa, Pakistan) for further process. From fresh leaves of $T$. elephantina, extract in water (TE.AQ), ethanol (TE.ET) and methanol (TE.ME) was prepared following the previously reported techniques (Rockwood et al., 2013). The whole experiment was carried in the microbiology laboratory at the department of Biotechnology, University of Malakand, and Khyber Pakhtunkhwa, Pakistan.

\section{Bacterial strains culturing}

The bacterial strains were cultured in nutrient broth (100 $\mathrm{mL}$ ) i.e. peptone, 1.5 gram, $\mathrm{NaCl}, 0.6$ gram, Yeast extract, 0.3 gram were dissolved in a flask having $30 \mathrm{~mL}$ distilled water and again added more water to raise its volume to $100 \mathrm{~mL}$. The dissolved media was sterilized at $121^{\circ} \mathrm{C}$ for 20 minutes in an autoclave, to culture the bacteria. Nutrient agar (Sigma Aldrich) was made in flask, sterilized in an autoclave and poured in petri plates for solidification (Ali et al., 2012; Singh et al., 2017).

These bacterial strains include both gram positive and gram negative bacteria such as Staphylococcus aureus (S. aureus), Staphylococcus epidermidis (S. epidermidis), Streptococcus pyogen (S. pyogenes), Escherichia coli (E. coli), Klebsiella pneumonia (K. pneumonia), Proteus vulgaris (P. vulgaris), Pseudomonas aeruginosa (P. aeruginosa) and Salmonella typhi (S. Typhi), respectively.

The bacterial strains were placed into a vessel of specific nutrient medium, and the vessel was vortexed to make a homogeneous bacterial suspension. The resulting inoculum suspension comprises $5 \times 10^{7}$ to $5 \times 10^{8} \mathrm{CFU} / \mathrm{ml}$ for gramnegative and gram-positive and can be used instantly. This range is same to the $0.5 \mathrm{McF}$ arland standard (Maksoud et al., 2018).

\section{In-vitro antibacterial activity of TE.AQ, TE.ET and TE.ME}

Disc diffusion method was used to evaluate the antibacterial effect of TE.AQ, TE.ET and TE.ME at a concentration of 5, 15, 25, 50 and $100 \mathrm{mg} / \mathrm{dL}$. After solidification of nutrient agar in petri plates, individual plates was inoculated with its respective bacterium (cultured in nutrient broth), through cotton swab, bacterium was uniformly distributed on the surface of plate. About $6 \mathrm{~mm}$ diameter discs were placed on the petri plates after inoculation of bacteria. Then $10 \mu \mathrm{L}$ amounts of different concentrations of extracts were applied to each disc pipette along with a standard antibiotic (Norfloxacine). The antibacterial activities of the extracts were observed after 24 hours of the incubation $\left(35^{\circ} \mathrm{C}\right)$ temperature. The zones of inhibition produced by different concentrations of extracts were measured in triplicates to determine the efficacy of the extracts against various strains.

\section{In-vivo antibacterial activity of TE.AQ, TE.ET and TE.ME}

A total of sixty poultry one day old chicks were reared in Bio Park, University of Malakand. These chicks were vaccinated for different diseases according to its schedule. Pseudomonas aeruginosa was selected for in-vivo study. Ethical Committee of the Department of Biotechnology, University of Malakand approved the experimental protocols and ensured its compliance with provisions of the "Animal Bye-Laws 2008, Scientific Procedures Issue-I of the University of Malakand". As the extract was highly effective against $P$. aeruginosa. The bacteria was administered intra peritonealy at the rate of 3 $x 10^{8} / 0.2 \mathrm{~mL}$, to all chicks except group (NC), according to the previously reported procedure Singh et al. (2017). After the occurrence of clinical signs and symptoms, all the animals were treated orally with TE.AQ, TE.ET and TE.ME for 15 days. At the age of 28 days, ' 36 ' chicks were selected and divided into seven groups, each group had six chicks.

Group NC: served as negative control.

Group PC: served as positive control.

Group NF: treated with Norfloxacine (NF) standard drug at a dose of $100 \mathrm{mg} / \mathrm{kg}$ body weight for 15 days.

Group TE.AQ: treated with TE.AQ at a dose of $300 \mathrm{mg} / \mathrm{kg}$ body weight for 15 days

Group TE.ET: fed with TE.ET at a dose of $300 \mathrm{mg} / \mathrm{kg}$ body weight for 15 days.

Group TE.ME: treated with TE.ME at a dose of $300 \mathrm{mg} / \mathrm{kg}$ body weight for 15 days.

\section{Blood collection and analysis}

Blood samples were taken from experimental animals at different intervals (day 1, 8 and 15) and were analyzed for hematological parameters such as total red blood cell count (TRBC), hemoglobin concentration ( $\mathrm{Hb})$, mean hemoglobin concentration (MHC), mean corpuscular haemoglobin concentration $(\mathrm{MCHC})$, mean corpuscular volume (MCV), total leukocyte count (TLC), neutrophils (N) and lymphocyte (L) count, according to previously described techniques (Ahmad $\&$ Zeb, 2019). The activities of liver enzymes such as alkaline phosphatase (ALP), Alanine aminotransferase (ALT) and Aspartate aminotransferase (AST) were also analyzed according to the enzymatic colorimetric method (Adorian et al., 2019).

\section{Statistical analysis}

All the results obtained were analyzed statistically. Mean and standard deviation of the values were calculated using Graph Pad Prism 5 software.

\section{RESULTS}

\section{In-vitro antibacterial activity of TE.AQ, TE.ET and TE.ME}

The in-vitro antibacterial potential of TE.AQ, TE.ET and TE.ME was evaluated at different concentration against clinically important gram negative and gram positive bacterial strains and was compared with Norfloxacine. The results showed that TE.ET and TE.ME extracts had strong inhibitory effect while TE.AQ was found less effective against various bacterial strains. The maximum antibacterial potential was found in TE.ME at a concentration of $100 \mathrm{mg} / \mathrm{dL}$ against P. aeruginosa with zone of inhibition (ZOI) of $19.67 \pm 0.057 \mathrm{~mm}$ as shown in Table 1. The S. aureus was observed susceptible to the same fraction with ZOI of $17.50 \pm 0.70 \mathrm{~mm}$ followed by S. pyogenes with ZOI of $15.9 \pm 0.10 \mathrm{~mm}$ at a concentration of $100 \mathrm{mg} / \mathrm{dL}$. The TE.ET had varied degrees of antibacterial effects against both gram negative and gram positive strains. However, the maximum activity against $P$. aeruginosa was observed at a concentration of 100 and $50 \mathrm{mg} / \mathrm{dL}$ with ZOI of $18.53 \pm 0.50$ and $17.67 \pm 0.57 \mathrm{~mm}$, respectively. It was also found active against $S$. pyogenes exhibiting $\mathrm{ZOI}$ of $16.2 \pm 1.55$ $\mathrm{mm}$ at a concentration of $100 \mathrm{mg} / \mathrm{dL}$. The TE.AQ showed little 
Table 1. In-vitro antibacterial activity TE.AQ, TE.ET and TE.ME against various bacterial strains

\begin{tabular}{|c|c|c|c|c|c|c|c|c|c|}
\hline \multirow{2}{*}{ Solvent } & \multirow{2}{*}{$\begin{array}{l}\text { Conc } \\
\text { (mg/dL) }\end{array}$} & \multicolumn{8}{|c|}{ Zone of Inhibition (mm) } \\
\hline & & S. aureus & S. epidermidis & S. pyogenes & E. coli & K. pneumonia & P. aeruginosa & P. vulgaris & S. Typhi \\
\hline \multirow[t]{5}{*}{ TE.AQ } & 5 & $3.66 \pm 0.47$ & $0.0 \pm 0.0$ & $0.0 \pm 0.0$ & $6.133 \pm 0.23$ & $0.0 \pm 0.0$ & $0.0 \pm 0.0$ & $5.03 \pm 0.057$ & $0.0 \pm 0.0$ \\
\hline & 15 & $5.86 \pm 0.057$ & $0.0 \pm 0.0$ & $0.0 \pm 0.0$ & $9.833 \pm 0.20$ & $0.0 \pm 0.0$ & $0.0 \pm 0.0$ & $6.96 \pm 0.057$ & $0.0 \pm 0.0$ \\
\hline & 25 & $8.50 \pm 0.20$ & $9.9 \pm 0.05$ & $0.0 \pm 0.0$ & $7.167 \pm 0.15$ & $1.63 \pm 0.057$ & $0.0 \pm 0.0$ & $9.23 \pm 0.49$ & $1.23 \pm 0.20$ \\
\hline & 50 & $9.13 \pm 0.13$ & $9.16 \pm 0.23$ & $0.0 \pm 0.0$ & $8.867 \pm 0.25$ & $1.90 \pm 0.10$ & $0.0 \pm 0.0$ & $10.6 \pm 0.57$ & $2.80 \pm 0.10$ \\
\hline & 100 & $13.0 \pm 0.50$ & $10.3 \pm 0.57$ & $11.33 \pm 0.57$ & $5.333 \pm 0.25$ & $3.73 \pm 0.25$ & $0.0 \pm 0.0$ & $12.9 \pm 0.10$ & $5.10 \pm 0.17$ \\
\hline \multirow[t]{5}{*}{ TE.ET } & 5 & $5.33 \pm 0.05$ & $7.06 \pm 0.05$ & $0.00 \pm 0.0$ & $4.27 \pm 0.15$ & $0.0 \pm 0.00$ & $11.3 \pm 1.528$ & $4.06 \pm 0.11$ & $0.0 \pm 0.0$ \\
\hline & 15 & $5.96 \pm 0.057$ & $5.90 \pm 0.10$ & $10.0 \pm 0.1$ & $4.86 \pm 0.057$ & $0.0 \pm 0.0$ & $12.9 \pm 0.75$ & $6.06 \pm 0.11$ & $2.20 \pm 0.26$ \\
\hline & 25 & $7.96 \pm 0.11$ & $7.30 \pm 0.10$ & $10.3 \pm 0.60$ & $7.36 \pm 0.208$ & $4.03 \pm 0.11$ & $14.87 \pm 0.20$ & $9.96 \pm 0.05$ & $2.03 \pm 0.11$ \\
\hline & 50 & $11.9 \pm 0.79$ & $9.00 \pm 1.30$ & $12.0 \pm 0.28$ & $9.96 \pm 0.057$ & $4.33 \pm 0.15$ & $17.67 \pm 0.57$ & $10.6 \pm 0.10$ & $3.03 \pm 0.15$ \\
\hline & 100 & $14.4 \pm 0.43$ & $10.6 \pm 0.57$ & $16.2 \pm 1.55$ & $12.97 \pm 0.05$ & $5.33 \pm 0.30$ & $18.53 \pm 0.50$ & $15.0 \pm 0.36$ & $8.30 \pm 0.60$ \\
\hline \multirow[t]{5}{*}{ TE.ME } & 5 & $7.33 \pm 0.10$ & $7.10 \pm 0.26$ & $4.96 \pm 0.20$ & $5.93 \pm 0.11$ & $0.0 \pm 0.0$ & $8.20 \pm 0.60$ & $6.86 \pm 0.15$ & $1.90 \pm 0.10$ \\
\hline & 15 & $8.00 \pm 0.10$ & $7.66 \pm 0.57$ & $6.30 \pm 0.20$ & $6.90 \pm 0.10$ & $0.0 \pm 0.0$ & $9.06 \pm 1.52$ & $7.03 \pm 0.05$ & $1.80 \pm 0.10$ \\
\hline & 25 & $8.03 \pm 0.15$ & $8.00 \pm 0.10$ & $7.50 \pm 0.20$ & $8.26 \pm 0.37$ & $1.76 \pm 0.15$ & $14.00 \pm 1.00$ & $7.96 \pm 0.05$ & $1.40 \pm 0.17$ \\
\hline & 50 & $13.70 \pm 0.65$ & $9.93 \pm 0.05$ & $9.96 \pm 0.05$ & $9.83 \pm 0.64$ & $2.50 \pm 0.17$ & $14.97 \pm 0.11$ & $9.96 \pm 0.05$ & $4.33 \pm 0.2$ \\
\hline & 100 & $17.50 \pm 0.70$ & $11.6 \pm 0.5$ & $15.9 \pm 0.1$ & $13.8 \pm 0.49$ & $3.80 \pm 0.36$ & $19.67 \pm 5.77$ & $13.3 \pm 0.57$ & $6.667 \pm 0.57$ \\
\hline Norfloxa & 50 & $22.33 \pm 0.57$ & $23.67 \pm 0.57$ & $21.33 \pm 0.57$ & $19.37 \pm 0.32$ & $20.77 \pm 0.68$ & $21.50 \pm 0.62$ & $19.87 \pm 0.35$ & $18.77 \pm 0.90$ \\
\hline
\end{tabular}

NC: negative control, PC: positive control, NF: Norfloxacine treated group at a dose of $100 \mathrm{mg} / \mathrm{kg}$, TE.AQ: group treated with TE.AQ at a dose of 300 $\mathrm{mg} / \mathrm{kg}$, TE.ET: group fed with TE.ET at a dose of $300 \mathrm{mg} / \mathrm{kg}$, TE.ME: group administered with TE.ME at a dose of $300 \mathrm{mg} / \mathrm{kg}$

Table 2. Weight (grams) of the chicks at different time periods

\begin{tabular}{llll}
\hline Groups & Day zero & Day $8^{\text {th }}$ & Day 15 \\
\hline Negative control & $396 \pm 1.0$ & $467 \pm 1.0$ & $491 \pm 1.09$ \\
Positive control & $352 \pm 1.0$ & $345 \pm 1.0$ & $340 \pm 1.06$ \\
NF $(100 \mathrm{mg} / \mathrm{kg})$ & $420 \pm 1.0$ & $410 \pm 1.0$ & $480 \pm 1.07$ \\
TE.AQ $(300 \mathrm{mg} / \mathrm{kg})$ & $423 \pm 1.0$ & $414 \pm 1.0$ & $427 \pm 1.01$ \\
TE.ET $(300 \mathrm{mg} / \mathrm{kg})$ & $431 \pm 1.0$ & $429 \pm 1.0$ & $472 \pm 1.04$ \\
TE.ME $(300 \mathrm{mg} / \mathrm{kg})$ & $437 \pm 1.0$ & $425 \pm 1.0$ & $481 \pm 1.05$ \\
\hline
\end{tabular}

NC: negative control, PC: positive control, NF: Norfloxacine treated group at a dose of $100 \mathrm{mg} / \mathrm{kg}$, TE.AQ: group treated with TE.AQ at a dose of $300 \mathrm{mg} / \mathrm{kg}$, TE.ET: group fed with TE.ET at a dose of $300 \mathrm{mg} / \mathrm{kg}$, TE.ME: group administered with TE.ME at a dose of 300 .

inhibitory effect against few strains but was not significant in comparison with the standard drug (norfloxacine). The TE.ME was found active against seven of eight tested bacterial strains which confirmed the antibacterial efficacy of Typha elephantina leaves extract. The most sensitive bacteria, $P$. aeruginosa was selected for in-vivo studies and the effect of tested samples was evaluated.

\section{In-vivo study}

The in-vivo antibacterial study of TE.AQ, TE.ET and TE.ME against $P$. aeruginosa was carried out in chicks model. All chicks were weighted before, during and after treatment. There was a significant decrease in weight of the infected chicks as compared to normal control, shown in Table 2. However, when treatment was completed, significant normal body weight was regained in animals fed with norfloxacine (NF) and TE.ME, while the TE.AQ and TE.ET showed no weight gain effects. Complete blood profile of all the groups were studied before experiment and during infection at day zero and during infection, at day $8^{\text {th }}$ of the treatment, shown in Table 3. From the results, it is clear that all the blood parameters in all the experimental groups were significantly $(p<0.05)$ impaired during infection when compared to the normal control group. After completion of treatment, at day $15^{\text {th }}$, animals in group that were infected with $P$. aeruginosa, but not treated, showed significantly $(P<0.05)$ abnormal hematological parameters, revealed toxicity. The animals administered with TE.ET and TE.ME at a dose rate of $300 \mathrm{mg} /$ kg body weight, showed remedial effects on hematological variables when compared to toxic control animals. However, a significant ameliorative effect was shown by TE.ME which confirmed its effectiveness against $P$. aeruginosa infection (Table 3). The significant elevation in the serum ALT, AST and ALP were observed in all groups during infection at day $8^{\text {th }}$ (Table 4). However, a significant reduction in serum enzymes activities was observed in animals administered with TE.ME, at day $15^{\text {th }}$ of treatment, when compared to normal control. Meanwhile, norfloxacine (NF) feed animals showed the results which were in normal reference range when compared to positive control and normal control groups.

\section{Gross pathological examination}

All the chicks were slaughtered at the end of the experiment on day $15^{\text {th }}$ and gross pathological findings were studied as shown in Figure $A 1, A 2, A 3, A 4, A 5$ and $A 6$. In Figure $A 1$, there is a normal liver having no lesion with no alteration as compared to the positive control. The group that was infected but not treated had a severe lesion on the liver as shown in Figure A2. The TE.AQ group had almost the same lesions to that of the positive control. The liver of animals in TE.ET was found with reduced lesions, while the livers of the animals treated with TE.ME had normal liver histology. In the Figure B1, B2, B3, B4, B5, and B6, the lungs of the different groups have been shown. In Figure B1, there was normal lung having no lesions as compared to the positive control group. The group that was infected but not treated (B2) had haemomoraghic lungs. The Norfloxacine treated group (B3) had a normal lung. It can be concluded that TE.ME has better potential against $P$. aeruginosa as compared to other groups. 
Table 3. Hematology of experimental groups

\begin{tabular}{|c|c|c|c|c|c|c|}
\hline & Normal control & Positive control & Norfloxacine & TE.AQ & TE.ET & TE.ME \\
\hline \multicolumn{7}{|l|}{ Day zero } \\
\hline $\mathrm{TRBC} \times 10^{3} / \mathrm{mm}^{3}$ & $3.23 \pm 0.15$ & $3.33 \pm 0.208$ & $3.37 \pm 0.15$ & $3.35 \pm 0.01$ & $3.36 \pm 0.15$ & $3.25 \pm 0.015$ \\
\hline $\mathrm{Hb} \mathrm{g} / \mathrm{dL}$ & $11.4 \pm 0.13$ & $12.0 \pm 1.0$ & $12.70 \pm 0.10$ & $12.4 \pm 0.15$ & $12.61 \pm 0.10$ & $11.75 \pm 0.15$ \\
\hline $\mathrm{MCH}(\mathrm{FI})$ & $46.00 \pm 1.0$ & $41.00 \pm 1.04$ & $44.00 \pm 1.0$ & $38.56 \pm 1.0$ & $35.46 \pm 1.0$ & $47.34 \pm 1.0$ \\
\hline $\mathrm{MCHC}(\%)$ & $30.00 \pm 1.04$ & $31.00 \pm 1.0$ & $35.00 \pm 1.0$ & $33.34 \pm 1.0$ & $27.33 \pm 0.57$ & $28.53 \pm 1.02$ \\
\hline $\operatorname{MCV}(\mu 3)$ & $114 \pm 1.03$ & $102.00 \pm 1.03$ & $139.00 \pm 1.0$ & $136.23 \pm 1.0$ & $104.64 \pm 1.0$ & $117.55 \pm 1.01$ \\
\hline TLC $\times 10^{6} / \mathrm{mm}^{3}$ & $19.2 \pm 0.1$ & $19.50 \pm 0.05$ & $19.90 \pm 0.01$ & $19.47 \pm 0.1$ & $19.73 \pm 0.1$ & $19.16 \pm 0.01$ \\
\hline N (\%) & $34.00 \pm 1.01$ & $36.00 \pm 1.07$ & $37.00 \pm 1.0$ & $33.64 \pm 1.0$ & $38.56 \pm 1.0$ & $38.67 \pm 1.06$ \\
\hline L (\%) & $53.00 \pm 1.0$ & $53.00 \pm 1.02$ & $51.00 \pm 1.0$ & $54.25 \pm 1.0$ & $54.45 \pm 1.0$ & $55.23 \pm 1.07$ \\
\hline \multicolumn{7}{|l|}{ Day $8^{\text {th }}$} \\
\hline $\mathrm{TRBC} \times 10^{3} / \mathrm{mm}^{3}$ & $3.24 \pm 0.1 a$ & $2.67 \pm 0.01 b$ & $2.7 \pm 0.015 c$ & $2.69 \pm 0.020 b$ & $2.75 \pm 0.010 c$ & $2.77 \pm 0.020 c$ \\
\hline $\mathrm{Hb} \mathrm{g} / \mathrm{dL}$ & $11.33 \pm 0.1 a$ & $7.53 \pm 0.05 b$ & $8.74 \pm 0.066 d$ & $7.98 \pm 0.0057 c$ & $8.40 \pm 0.100 d$ & $8.467 \pm 0.251 d$ \\
\hline $\mathrm{MCH}(\mathrm{FI})$ & $45.37 \pm 0.57 a$ & $26.93 \pm 0.86 b$ & $34.28 \pm 0.59 c$ & $29.10 \pm 0.19 d$ & $30.76 \pm 0.78 d$ & $30.92 \pm 1.00 d$ \\
\hline $\mathrm{MCHC}(\%)$ & $35.37 \pm 1.00 a$ & $23.51 \pm 0.56 b$ & $28.96 \pm 0.50 c$ & $25.14 \pm 0.52 d$ & $26.93 \pm 0.44 \mathrm{e}$ & $26.56 \pm 0.50 \mathrm{e}$ \\
\hline $\operatorname{MCV}(\mu 3)$ & $116.63 \pm 1.0 a$ & $93.44 \pm 1.34 b$ & $108.74 \pm 2.08 c$ & $99.33 \pm 0.57 d$ & $104.05 \pm 1.00 \mathrm{e}$ & $104.70 \pm 0.57 e$ \\
\hline TLC $\times 10^{6} / \mathrm{mm}^{3}$ & $19.52 \pm 0.1 a$ & $24.00 \pm 1.00 b$ & $19.67 \pm 0.57 c$ & $22.13 \pm 0.47 d$ & $21.67 \pm 0.57 d$ & $20.67 \pm .57 \mathrm{~cd}$ \\
\hline $\mathrm{N}(\%)$ & $35.76 \pm 1.00 a$ & $50.56 \pm 1.0 b$ & $40.67 \pm 0.57 c$ & $48.33 \pm 1.52 b d$ & $44.33 \pm 1.15 d$ & $45.33 \pm 1.52 d$ \\
\hline L (\%) & $52.35 \pm 1.00 a$ & $39.22 \pm 0.37 b$ & $47.00 \pm 0.50 c$ & $41.33 \pm 1.57 \mathrm{bd}$ & $45.33 \pm 1.52 \mathrm{e}$ & $44.00 \pm 0.51 \mathrm{e}$ \\
\hline \multicolumn{7}{|l|}{ Day $15^{\text {th }}$} \\
\hline $\mathrm{TRBC} \times 10^{3} / \mathrm{mm}^{3}$ & $3.32 \pm 0.1 a$ & $2.81 \pm 0.1 b$ & $3.31 \pm 0.04 a$ & $2.99 \pm 0.01 b c$ & $3.20 \pm 0.05 a$ & $3.22 \pm 0.09 a$ \\
\hline $\mathrm{Hb} \mathrm{g} / \mathrm{dL}$ & $11.48 \pm 0.1 a$ & $7.53 \pm 0.01 b$ & $11.41 \pm 0.64 a$ & $8.98 \pm 0.005 b$ & $10.40 \pm 0.10 c$ & $11.47 \pm 0.25 a$ \\
\hline $\mathrm{MCH}(\mathrm{FI})$ & $47.34 \pm 1.0$ & $29.60 \pm 0.66 b$ & $45.95 \pm 1.00 a$ & $32.76 \pm 1.34 \mathrm{bc}$ & $40.43 \pm 1.06 d$ & $43.92 \pm 0.13 a$ \\
\hline $\mathrm{MCHC}(\%)$ & $35.49 \pm 1.00$ & $25.51 \pm 0.79 b$ & $36.63 \pm 1.73 a$ & $30.81 \pm 0.46 c$ & $33.60 \pm 0.75 d$ & $36.90 \pm 0.69 a$ \\
\hline $\operatorname{MCV}(\mu 3)$ & $116.34 \pm 1.0 \mathrm{a}$ & $94.47 \pm 1.3 b$ & $114.78 \pm 2.0 a$ & $102.73 \pm 2.5 c$ & $108.37 \pm 1.1 d$ & $114.76 \pm 1.5 a$ \\
\hline TLC $\times 10^{6} / \mathrm{mm}^{3}$ & $19.56 \pm 0.1 a$ & $24.74 \pm 0.1 b$ & $19.54 \pm 0.1 a$ & $22.86 \pm 0.1 c$ & $21.14 \pm 0.1 c$ & $20.03 \pm 0.1 a$ \\
\hline N (\%) & $39.89 \pm 1.00 a$ & $55.34 \pm 1.0 \mathrm{~b}$ & $40.48 \pm 1.0 a$ & $46.49 \pm 1.0 c$ & $43.51 \pm 1.0 d$ & $40.97 \pm 0.5 a$ \\
\hline L (\%) & $48.34 \pm 1.00 a$ & $36.56 \pm 1.0 \mathrm{~b}$ & $47.49 \pm 1.0 a$ & $39.28 \pm 1.0 b c$ & $44.74 \pm 1.0 \mathrm{~d}$ & $46.68 \pm 1.0 a$ \\
\hline
\end{tabular}

Mean values in the same row having different superscripts (a-e) are significantly different $(P<0.05)$. NC: negative control, PC: positive control, NF: Norfloxacine treated group at a dose of $100 \mathrm{mg} / \mathrm{kg}$, TE.AQ: group treated with TE.AQ at a dose of $300 \mathrm{mg} / \mathrm{kg}$, TE.ET: group fed with TE.ET at a dose of $300 \mathrm{mg} / \mathrm{kg}$, TE.ME: group administered with TE.ME at a dose of $300 \mathrm{mg} / \mathrm{kg}$.

Table 4. Liver biomarkers of experimental groups

\begin{tabular}{|c|c|c|c|c|c|c|}
\hline & Normal control & Positive control & Norfloxacine & TE.AQ & TE.ET & TE.ME \\
\hline \multicolumn{7}{|l|}{ Day zero } \\
\hline ALT U/L & $65.33 \pm 1.52$ & $66.00 \pm 1.73$ & $68.67 \pm 2.06$ & $65.00 \pm 1.00$ & $65.00 \pm 2.0$ & $62.67 \pm 1.53$ \\
\hline ALP U/L & $35.67 \pm 1.52$ & $33.00 \pm 2.64$ & $37.33 \pm 2.51$ & $38.00 \pm 1.00$ & $39.33 \pm 0.57$ & $38.67 \pm 1.15$ \\
\hline AST U/L & $137.32 \pm 2.08$ & $139.3 \pm 1.52$ & $139.0 \pm 2.00$ & $137.0 \pm 1.00$ & $135.73 \pm 1.52$ & $136.33 \pm 1.52$ \\
\hline \multicolumn{7}{|l|}{ Day $8^{\text {th }}$} \\
\hline ALT U/L & $60.00 \pm 1.00 a$ & $140.0 \pm 2.64 b$ & $121.0 \pm 1.00 c$ & $135.0 \pm 1.73 d$ & $129.35 \pm 0.57 c$ & $125.75 \pm 2.51 c$ \\
\hline ALP U/L & $42.00 \pm 2.64 a$ & $96.33 \pm 2.08 b$ & $88.00 \pm 1.44 c$ & $81.33 \pm 0.74 d$ & $75.67 \pm 1.52 \mathrm{e}$ & $76.33 \pm 1.52 \mathrm{e}$ \\
\hline AST/ U/L & $137.04 \pm 1.00 a$ & $233.32 \pm 2.08 b$ & $212.71 \pm 2.08 c$ & $222.77 \pm 0.28 d$ & $218.03 \pm 1.00 \mathrm{e}$ & $213.38 \pm 2.02 c$ \\
\hline \multicolumn{7}{|l|}{ Day $15^{\text {th }}$} \\
\hline ALT U/L & $60.00 \pm 2.00 a$ & $98.33 \pm 1.15 b$ & $59.67 \pm 2.30 a$ & $78.67 \pm 0.57 c$ & $67.33 \pm 1.52 d$ & $62.33 \pm 2.08 a$ \\
\hline ALP U/L & $34.67 \pm 2.08 a$ & $85.33 \pm 1.52 b$ & $35.00 \pm 1.00 a$ & $69.33 \pm 1.52 c$ & $53.00 \pm 2.64 d$ & $35.33 \pm 1.52 \mathrm{a}$ \\
\hline AST U/L & $138.09 \pm 1.00 a$ & $231.02 \pm 2.00 b$ & $134.04 \pm 1.00 a$ & $198.79 \pm 1.52 c$ & $166.74 \pm 2.51 d$ & $137.30 \pm 2.64 a$ \\
\hline
\end{tabular}

NC: negative control, PC: positive control, NF: Norfloxacine treated group at a dose of $100 \mathrm{mg} / \mathrm{kg}$, TE.AQ: group treated with TE.AQ at a dose of $300 \mathrm{mg} / \mathrm{kg}$, TE.ET: group fed with TE.ET at a dose of $300 \mathrm{mg} / \mathrm{kg}$, TE.ME: group administered with TE.ME at a dose of $300 \mathrm{mg} / \mathrm{kg}$.

\section{DISCUSSION}

The incidence of life-threatening disease caused by pathogens has increased globally and is one of the causes of morbidity and mortality in the developed nation (Rather et al., 2017). Gram-positive bacteria are the leading cause of a diverse range of lethal infections such as skin and softtissue infections and urinary tract infections (UTI), however, clinical microbiologists thought that gram-negative bacteria pose a big hazard to public health (Wright et al., 2017). A diverse array of human infections including pneumonia, necrosis, inflammation and hemorrhage in lungs and other tissues caused by $P$. aeruginosa and $K$. pneumonia. Similarly, $E$. coli caused chronic urinary tract infections and has been a cause of transferring antibiotic-resistant genes from infected food animals to human (Foxman, 2010). It is necessary to control microbial infections and its resistance to various drugs by developing' new antibiotic. Herbal medicines are very potent and have minimum side-effects. This project was done to determine the effect of leaf extract of Typha elephantina against eight selected bacterial strains. Highly significantly antibacterial potential was found in TE.ME at a concentration 


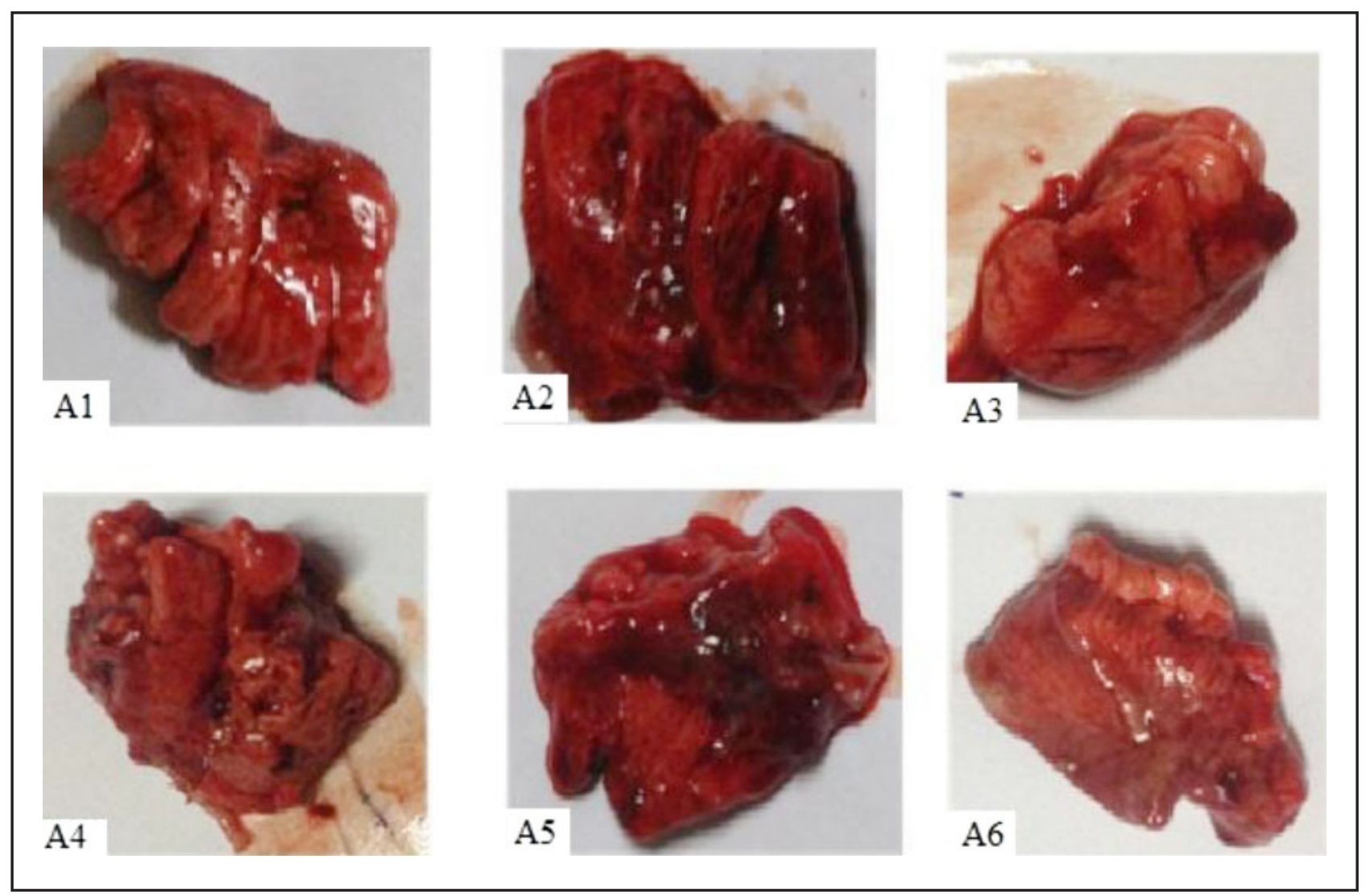

Figure 1. Gross pathological findings of lungs of all the chicks.

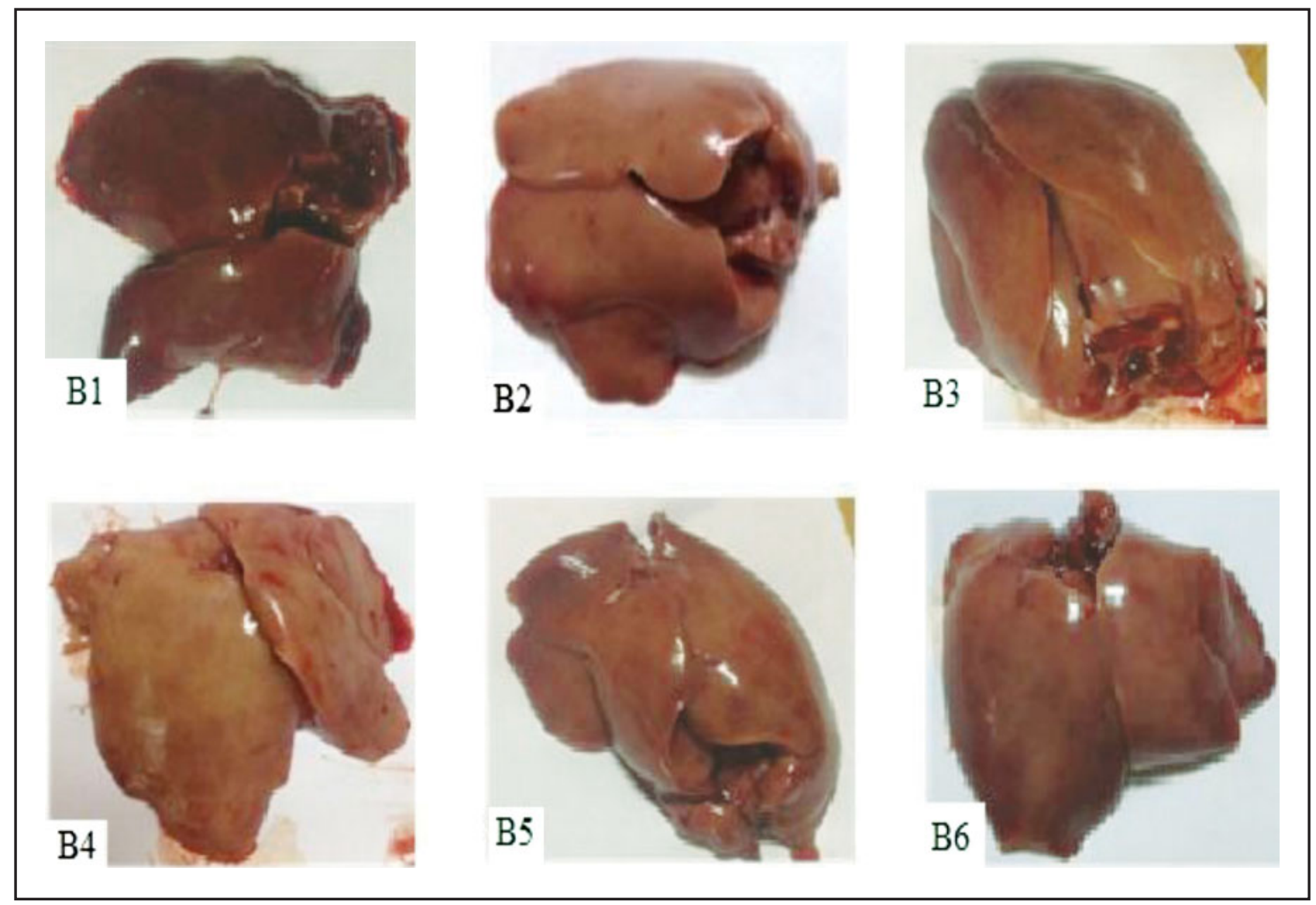

Figure 2. Gross pathological findings of livers of all the chicks. 
of $100 \mathrm{mg} / \mathrm{dL}$ against $P$. aeruginosa. While TE.ME showed better effect at a concentration of $100 \mathrm{mg} / \mathrm{dL}$ against $P$. aeruginosa with zone of inhibition (ZOI) of $19.67 \pm 0.057 \mathrm{~mm}$. In another hand TE.AQ showed little inhibitory effect against few strains but was not significant. In comparison with the standard drug (Norfloxacin) the effects of the extracts were nonsignificant. This potent antimicrobial action of TE.ME against S. aureusis in agreement with the results of other researcher which showed the same effect in Cannabis sativa against multiple strains such as Staphylococcus aureus, Pseudomonas aeruginosa, Escherichia coli (Forouzanfar et al., 2014). The screening of TE.ME and TE.ET against S. pyogenes exhibit significant inhibition activity at all concentration, while the TE.AQ was active only at $100 \mathrm{mg} / \mathrm{dL}$. These findings are similar to antibacterial effects of kalonji oil and its comparison with methanolic and aqueous extracts of Nigella sativa seeds. E. coli was sensitive to all extracts at all concentrations, but good activity was found by the TE.ME as compared to TE.ET and TE.AQ, respectively (Singh et al., 2017). K. pneumonia showed resistance to both TE.AQ and TE.ME at concentration of 50 and $100 \mathrm{mg} / \mathrm{dL}$, however good antimicrobial activity was exhibited by TE.ET at a concentration of 25 and $50 \mathrm{mg} / \mathrm{dL}$.

$P$. aeruginosa displayed the highest sensitivity to TE.ME and TE.ET but showed resistance to TE.AQ for 25 and $50 \mathrm{mg} / \mathrm{dL}$ of concentrations. The $P$. aeruginosa was found to be the most sensitive among all studied bacteria strains. These findings are in correlation with the finding of Adeosun et al. (2016). Maximum antibacterial activity was given by the TE.ET against $P$. vulgaris as compared to TE.AQ and TE.ME, the bacteria showed no resistance at any concentration. S. Typhi was found to be the most resistant among all having the lowest zone of inhibition in response to TE.ME, TE.ET and TE.AQ for all concentrations. From the result of this study, the TE.ME revealed high inhibitory effects against most of the tested bacteria. The diverse antibacterial activity recorded for different extracts of T.E could be attributed to various metabolites found in the plant, ensuring the fact that these phytochemicals are the major antibacterial agents constituted in plant (Asong et al., 2019). P. aeruginosa is an opportunistic pathogen entering and populated in embryonated eggs causing the in-shell death of embryos and newly hatched chicks (Umar et al., 2017). P. aeruginosa is, a nonspore forming and noncapsulated gram-negative bacillus, causing lower respiratory tract infections in chicken, also responsible for $30 \%$ of pneumonia, $19 \%$ of urinary tract infections, and $10 \%$ of bloodstream infections. Loss in body weight was noted in the infected chicken as compared to the negative control. It has been shown that weight loss after 15 days of $P$. aeruginosa infection, may be due to the concentration of pro-inflammatory cytokine levels after inoculation of chicks with $P$. aeruginosa and also loss of skeletal muscle mass. All tested groups showed abnormal hematological parameters during $P$. aeruginosa infection at day $8^{\text {th }}$ of the experiment as compared to the normal control group. Significantly reduced levels of TRBC, $\mathrm{Hb}$ and related parameters such as $\mathrm{MCH}, \mathrm{MCHC}$ and $\mathrm{MCV}$ were observed in all experimental groups, specifically in positive control group. While, significantly high a level of TLC was observed in all tested groups. The parallel study has been reported by Tripathi et al. (2017) which showed a significant decrease in TRBC count and $\mathrm{Hb}$ level in infected in Japanese quail, increase in TLC was found in infected quails. It has been observed that pyocyanine, secreted by $P$. aeruginosa may cause the suppression of specific defense mechanisms and boost harmful inflammatory responses of the host during infection with $P$. aeruginosa.

\section{CONCLUSION}

Antibiotics have been used extensively in in order to treat and inhibit bacterial diseases. They have also been used in lesser amount in feed as growth promoters. Such trend has enhanced poultry performance excellently and economically but an increase in numbers of antibiotic-resistant bacterial strains, did occur which can be spread from poultry to humans via the food chain with serious consequences on public health. Therefore it has been conclude from present in vitro and in vivo study that the T. elephantina leave's methanolic extract, (TE.ME) is very potent against most of the bacterial strains. Followed by the ethanolic extract (TE.ET) and aqueous extract (TE.AQ) of the plant respectively. Current in vivo study indicated that all three types of extracts i.e (TE.ET), (TE.ME) and (TE.AQ) have significant antibacterial efficacy as revealed from histopathological findings. The extract is also beneficial for most of hematological and liver parameters. In addition, $T$. elephantina extract has potent antioxidant capacity. Therefor this plant extract can also be used scientifically for other fatal and chronic diseases.

Current research work revealed the antibacterial potential of Typha elephantina which may be due to the presence of certain secondary metabolites. Thus this plant may be used for treating various bacterial infections especially caused by $P$. aeruginosa. Hence this research recommends that the Typha elephantina possess best antioxidant property, which could be used as best source of advance medication. Thus further exploration of the plant is required.

\section{ACKNOWLEDGMENT}

Microbiology lab at University of Malakand Lower Dir KPK Pakistan is acknowledged for providing facilities to accomplish this research work.

\section{Conflict of interest}

All the authors have no conflict of interest and read the manuscript properly and approved for publication.

\section{REFERENCES}

Adeosun, O.M., Arotupin, D.J., Toba, O.A. \& Adebayo, A. (2016). Antibacterial activities and phytochemical properties of extracts of Dioscorea bulbifera Linn (Air Potatoe) tubers and peels against some pathogenic bacteria. The Journal of Phytopharmacology 5: 20-26.

Adorian, T.J., Jamali, H., Farsani, H.G., Darvishi, P., Hasanpour, S., Bagheri, T. \& Roozbehfar, R. (2019). Effects of probiotic bacteria Bacillus on growth performance, digestive enzyme activity, and hematological parameters of Asian sea bass, Lates calcarifer (Bloch). Probiotics and Antimicrobial Proteins 11: 248-255. https://doi.org/10.1007/ s12602-018-9393-z

Ahameethunisa, A.R. \& Hopper, W. (2010). Antibacterial activity of Artemisia nilagirica leaf extracts against clinical and phytopathogenic bacteria. BMC Complementary and Alternative Medicine 10: 6. https://doi.org/10.1186/1472-688210-6

Ahmad, S. \& Zeb, A. (2019). Effects of phenolic compounds from aqueous extract of Trifolium repens against acetaminophen-induced hepatotoxicity in mice. Journal of Food Biochemistry 43: e12963. https://doi.org/10.1111/ jfbc.12963 
Ali, E.M., Almagboul, A.Z., Khogali, S.M. \& Gergeir, U.M. (2012). Antimicrobial activity of Cannabis sativa L. Chinese Medicine 3: 61-64. https://doi.org/10.4236/cm.2012.31010

Al-Salt, J. (2012). Antimicrobial activity of crude extracts of some plant leaves. Research Journal of Microbiology 7: 5967. https://doi.org/10.3923/jm.2012.59.67

Asong, J.A., Amoo, S.O., Mcgaw, L.J., Nkadimeng, S.M., Aremu, A.O. \& Otang-Mbeng, W. (2019). Antimicrobial activity, antioxidant potential, cytotoxicity and phytochemical profiling of four plants locally used against skin diseases. Plants 8: 350. https://doi.org/10.3390/plants8090350

Emiru, Y.K., Siraj, E.A., Teklehaimanot, T.T. \& Amare, G.G. (2019). Antibacterial Potential of Aloe weloensis (Aloeacea) leaf latex against gram-positive and gram-negative bacteria strains. International Journal of Microbiology 2019: 5328238. https://doi.org/10.1155/2019/5328238

Fankam, A.G., Kuiate, J.R. \& Kuete, V. (2014). Antibacterial activities of Beilschmiedia obscura and six other Cameroonian medicinal plants against multi-drug resistant gram-negative phenotypes. BMC Complementary and Alternative Medicine 14: 241. https://doi.org/10.1186/ 1472-6882-14-241

Forouzanfar, F., Bazzaz, B.S.F. \& Hosseinzadeh, H. (2014). Black cumin (Nigella sativa) and its constituent (thymoquinone): a review on antimicrobial effects. Iranian Journal of Basic Medical Sciences 17: 929-938.

Foxman, B. (2010). The epidemiology of urinary tract infection. Nature Reviews Urology 7: 653-660. https://doi.org/10.1038/ nrurol.2010.190

Ha, Y.H., Gil, H.Y., Lee, J., Lee, K.H., Lee, D.H., Son, D.C. \& Chang, K.S. (2019). Notes on Sparganium coreanum (Typhaceae) rediscovered on the Korean Peninsula. Korean Journal of Plant Taxonomy 49: 203-208. https://doi.org/10.11110/ kjpt.2019.49.3.203

Inglin, R.C., Stevens, M.J., Meile, L., Lacroix, C. \& Meile, L. (2015). High-throughput screening assays for antibacterial and antifungal activities of Lactobacillus species. Journal of Microbiological Methods 114: 26-29. https://doi.org/10.1016/ j.mimet.2015.04.011

Lewis, K. (2013). Platforms for antibiotic discovery. Nature Reviews Drug Discovery 12: 371-387. https://doi.org/10.1038/ $\operatorname{nrd} 3975$

Maksoud, M.A., El-Sayyad, G.S., Ashour, A., El-Batal, A.I., AbdElmonem, M.S., Hendawy, H.A., Abdel-Khalek, E., Labib, S., Abdeltwab, E. \& El-Okr, M. (2018). Synthesis and characterization of metals-substituted cobalt ferrite [Mx Co (1-x) Fe2O4; (M= Zn, Cu and $M n ; x=0$ and 0.5)] nanoparticles as antimicrobial agents and sensors for Anagrelide determination in biological samples. Materials Science and Engineering 92: 644-656. https://doi.org/10.1016/ j.msec.2018.07.007

Rather, I.A., Kim, B.C., Bajpai, V.K. \& Park, Y.H. (2017). Selfmedication and antibiotic resistance: Crisis, current challenges, and prevention. Saudi Journal of Biological Sciences 24: 808-812. https://doi.org/10.1016/j.sjbs.2017. 01.004

Rockwood, J., Anderson, B. \& Casamatta, D. (2013). Potential uses of Moringa oleifera and an examination of antibiotic efficacy conferred by $M$. oleifera seed and leaf extracts using crude extraction techniques available to underserved indigenous populations. International Journal of Phytotherapy Research 3: 61-71.
Saleem, U., Khalid, S., Zaib, S., Anwar, F., Ahmad, B., Ullah, I., Zeb, A. \& Ayaz, M. (2020). Phytochemical analysis and wound healing studies on ethnomedicinally important plant Malva neglecta Wallr. Journal of Ethnopharmacology 249: 112401. https://doi.org/10.1016/j.jep.2019.112401

Shukla, S. \& Mishra, P. (2015). Pseudomonas aeruginosa infections in broiler chicks in Jabalpur. International Journal Experimental Research 6: 37-39.

Singh, B., Sinha, D. \& Bhardwaj, M. (2017). Antimicrobial activity of Kalonji Oil and its comparison with methanolic and aqueous extracts of Nigella sativa (Kalonji) seeds. Natural Products: An Indian Journal 13: 107.

Singh, R. (2015). Medicinal plants: A review. Journal of Plant Sciences 3: 50-55.

Tripathi, D., Kumar, A., Mondal, B. \& Joyti, P. (2017). Effect of dietary supplementation of Ajwain, hot red pepper and black pepper on the performance, haemato-biochemical and carcass characteristics of Japanese quail. Indian Journal of Poultry Science 52: 288-295. https://doi.org/10.5958/ 0974-8180.2017.00059.9

Umar, S., Guerin, J.L. \& Ducatez, M.F. (2017). Low pathogenic avian influenza and coinfecting pathogens: a review of experimental infections in avian models. Avian Diseases 61: 3-15. https://doi.org/10.1637/11514-101316-Review

Wright, H., Bonomo, R.A. \& Paterson, D.L. (2017). New agents for the treatment of infections with Gram-negative bacteria: restoring the miracle or false dawn? Clinical Microbiology and Infection 23: 704-712. https://doi.org/ 10.1016/j.cmi.2017.09.001

Zeb, A. (2020). Concept, mechanism and applications of phenolic antioxidants in foods. Journal of Food Biochemistry 44: e13394. https://doi.org/10.1111/jfbc.13394 